\title{
Journalists and conflicts of interest in science: beliefs and practices
}

\author{
Daniel M. Cook $^{1,}{ }^{*}$, Elizabeth A. Boyd ${ }^{2}$, Claudia Grossmann ${ }^{3}$, Lisa A. Bero ${ }^{4}$ \\ ${ }^{1}$ School of Community Health Sciences, Mailstop 274, University of Nevada, Reno, Nevada 89557, USA \\ ${ }^{2}$ Department of Pharmacy Practice and Science, University of Arizona, PO Box 210066, Tucson, Arizona 85712, USA \\ ${ }^{3}$ Biomedical Sciences, and ${ }^{4}$ Department of Clinical Pharmacy, University of California San Francisco, Box 0613, \\ San Francisco, California 94118, USA
}

\begin{abstract}
Amidst reports of science news omitting key information regarding financial ties in scientific research, the present study surveyed the practices of health and science journalists in the USA. We obtained opinions about financial ties and research funding in science and asked about any challenges to reporting this information. We conducted interviews with a targeted list of journalists who wrote newspaper stories on key topics during 2 recent years. The journalists were asked questions about the significance of financial ties in research, their methods for discovering financial ties, and any barriers to reporting financial ties. We found that 145 journalists wrote 1152 stories in 2 years, and we were able to interview 31 of them. Journalists understood the concerns of financial ties in science, but reporting them was not often a top priority. Journalists who reported on the top health and science stories of 2004 and 2005 had considerable awareness of the implications of potential conflicts of interest, but they applied divergent investigating and reporting practices attributable to various challenges. Constraints faced by journalists included time, space, difficulty finding objective sources, and editorial priorities. The generalizability of our conclusions is limited by the small number of journalists interviewed. Our experience reveals the challenges of surveying this small but important group.
\end{abstract}

KEY WORDS: Research ethics $\cdot$ Financial ties $\cdot$ Corporate funding $\cdot$ Print media $\cdot$ Science journalism Resale or republication not permitted without written consent of the publisher

\section{INTRODUCTION}

The print news media continue to represent an important source of science news and health information for the lay public and the scientific community (Winsten 1985, Phillips et al. 1991, Clark \& Illman 2006, Singh et al. 2007, Canales et al. 2008, Smith et al. 2008). However, when scientific research is reported in the news media, important information regarding context and methods is often lost (Pellechia 1997, Kua et al. 2004). Science journalism often fails to describe the limitations of the reported study, funding sources supporting the research, or financial conflicts of interests of investigators (Winsten 1985, Moynihan \& Sweet 2000, Caulfield 2004), even as financial ties between researchers and their corporate sponsors are increasing in prevalence and magnitude (Boyd \& Bero 2000,
Bok 2003, Boyd et al. 2003, Washburn 2005, Berman 2008). One study of 207 news stories on new drug therapies found that $85 \%$ cited experts with financial ties to the drug manufacturer, but that only about a third of these reported the relationship (Moynihan et al. 2000). Other studies found that health and science news stories infrequently describe the funders of research and the financial ties of researchers (Cook et al. 2007, Hochman et al. 2008, Schwitzer 2008).

Full public disclosure of financial ties in research has implications for research ethics, public understanding of the research results, and public confidence in science (Cho et al. 2000, Rosenstock \& Lee 2002). Financial ties most often refer to personal relationships between scientists and the companies whose products they study. These can include consulting fees, stock ownership, equity, patent royalties, honoraria, service 
on boards of directors or scientific advisory boards, and fees for participating in a speaker's bureau. Reporting funding sources, financial ties of investigators, and study limitations are important because of potential conflicts of interest that may bias or influence the objectivity of the science. Many scholars agree that the type of conflict of interest most likely to affect the public's trust is a financial conflict where the scientist might gain financially as a result of a particular research outcome (Baltimore 1989, Drazen \& Koski 2000, Friedman 2002).

Financial ties of investigators with companies that make the products they are testing are associated with the reporting of favorable research results and conclusions for the sponsor (Bekelman et al. 2003, Lexchin et al. 2003, Bero et al. 2007, Lesser et al. 2007). Biased research can be intentional or unintentional (Dana \& Loewenstein 2003), and can result from damaged objectivity at multiple stages in the research process, including conceptualization of the question, design of the research, conduct of the research, or publication (or not) of the research (Bero 2005). For these reasons, many scientific journals are now requiring that authors disclose sponsors, the role of the sponsor in the study, and any other financial ties and potential conflicts of interest (Campbell 2001, Kennedy 2004, Ancker \& Flanagin 2007), but similar requirements for the mainstream news media are unknown. Moreover, the news media have served as disseminators of messages from industry stakeholders casting doubt over scientific evidence (Stocking \& Holstein 2009).

Health and science news reporters may face several challenges when reporting on scientific discovery and clinical results. First, press releases are a critical source of information for science journalists, but they are usually incomplete (McInerney et al. 2004). Press releases from medical journals often omit key information, such as research funding, which makes the journalists' tasks more difficult (Woloshin \& Schwartz 2002). Press releases from pharmaceutical companies often omit study limitations and quantifiable results (Kuriya et al. 2008). Other sources of information for news stories, such as communication programs to accompany major discoveries, may not exist (Canales et al. 2008). A study that interviewed 22 science writers found that space limitations in news stories led writers to only include potential conflicts that they deemed 'major' or to report only corporate research funding (Geller et al. 2005). Additionally, journalists may not fully understand the definition, prevalence, and implications of potential conflicts of interest (Boffey et al. 1999). One study of genetic cloning research in the news found that the most frequent sources quoted had financial ties to the technology reported in the results (Hyde 2006).
Our objective was to investigate the perspective of journalists on the topic of reporting financial ties in scientific research. As part of a larger examination of the extent and nature of reporting of conflicts of interest and research in clinical, engineering, and basic science, we conducted a content analysis of 1152 newspaper stories and then surveyed the authors.

\section{METHODS}

We first identified the topics of top news stories in science from the past $5 \mathrm{yr}$ according to year-end lists published in 4 journals: Discovery, Scientific American, Popular Science, and Science. We excluded topics not relevant to basic science, clinical studies, and engineering, and then selected the top 15 for our study. These included global warming, nanotechnology, stem cells, gamma rays, new matter, aging, toxic exposures, infections disease, reproductive biology, genetics, genomics, cloning, cancer therapy, genetically modified organisms, and chemistry.

We searched Lexis/Nexis Academic News - which contains full-text news from a source list of about 260 major and regional newspapers and wire services in the USA - for stories on these topics from 2004 and 2005. Some of the topics were overly broad as search terms, so they were paired with the word 'study' or 'research' in order to find relevant stories describing new studies. We searched US News for each of the 4 regions in the database: Midwest, Northeast, Southeast, and West from January 1, 2004 to November 30, 2005. This yielded over 9800 hits on news stories. We included news stories from any section, but excluded obituaries, book reviews, editorials, and other items not reporting scientific research. We then conducted stratified sampling by randomly selecting 100 stories from each of the 15 topics, although several topics yielded fewer than 100 hits, in which case all stories were included. After eliminating any duplicates, our final sample consisted of 1152 news stories on the top 15 topics in new scientific and medical research. A separate analysis of these stories was reported previously: funders of the research were identified in $38 \%$ of stories, financial ties of the researchers were reported in $11 \%$ of stories, and $5 \%$ reported financial ties of sources quoted, while of 73 stories not reporting financial ties in the lay press, $27 \%$ publicly disclosed financial ties in scholarly journals (Cook et al. 2007).

Next, we identified the authors of 1152 stories $(n=145)$ and contacted them with an electronic survey instrument seeking more detailed information. Respondents were given the option to enter a raffle contest for a personal music player, and 2 were awarded. The survey included closed- and open-ended questions about (1) the significance of financial ties in research, (2) their methods for 
discovering financial ties, and (3) any barriers to reporting financial ties. The survey instrument was tested on a health science journalist whose suggestions were incorporated into the final set of questions. After the survey had been online for several months, we followed up with telephone calls to the nonresponsive authors. If the subject was reached, a graduate student researcher administered the same survey instrument orally by telephone at a mutually convenient time. The telephone interviews were transcribed and the responses from both web survey and telephone were entered into SPSS for data management purposes and analyzed together. Of the original list of 145 journalists, 102 declined to participate or were never located, 31 completed the survey either electronically or by telephone, and 12 never responded at all to several approaches. The study was approved by the University of California Committee on Human Research (\#H2758-25469-03B).

\section{RESULTS}

In total, 145 writers produced 1152 top news stories in health and science. The 31 journalists participating in the survey ranged in age between 27 and 61, and most were in their $40 \mathrm{~s}$ or $50 \mathrm{~s}$. All reported having a college education, 15 with journalism degrees, 3 with science or health majors, and 8 with graduate school or advanced degrees. Twenty-one respondents had worked more than $20 \mathrm{yr}$ as a journalist, and 15 had worked more than $10 \mathrm{yr}$ as a health and/or science reporter. The survey reached 19 men, 10 women, and 2 refused to give this information. All respondents but one claimed white or Caucasian/European ethnicity, and 1 person identified multiple ethnicities.

\section{Opinions of journalists about the significance of financial ties in research}

As shown in Table 1, $94 \%$ (29/31) of respondents report on financial ties at least 'sometimes' and $48 \%$ (15/31) seek out sources with no ties 'almost always'. When asked to explain why or why not they might seek a source with no financial ties, many responses listed the importance of credibility, balance, removal of bias, validity, impartiality, and objectivity. Those who did not seek out independent sources said that it was difficult to find appropriate experts without ties, and that they might ask someone unconnected to the project but without specific attention to financial tie status.

Of the surveyed journalists, $71 \%$ (22/31) affirmed that they routinely ask about scientists' financial ties (Table 2). Those who did not indicated that the question is not appropriate for every story or that the information may be found elsewhere or already known. Journalists were most concerned about the financial ties of clinical researchers. Several mentioned a notion that basic science was less susceptible to bias than research on potentially profitable drugs and devices (and so would only ask when writing stories about drugs). The reasons given for always asking about financial ties included identifying potential conflicts of interest and influence over direction of research, a belief that readers should have all the information, and news organization policy.

Table 1. Frequency with which polled journalists $(n=31)$ reported funding sources and sought independent sources

\begin{tabular}{lcccccc} 
Question & Always $\begin{array}{c}\text { Almost } \\
\text { always }\end{array}$ & Sometimes & Rarely Never Decline \\
\hline How often do you report on the funding sources for new research? & 3 & 8 & 18 & 1 & 1 \\
How often do you seek out sources without relevant financial ties? & 6 & 15 & 6 & 3 & 0 \\
1
\end{tabular}

Table 2. Polled journalists' opinions and practice related to reporting financial ties $(\mathrm{n}=31)$

\begin{tabular}{|c|c|c|c|}
\hline Question & Yes & No & Decline \\
\hline Do you routinely ask about scientists' financial ties when reporting on research? & 22 & 9 & 0 \\
\hline Are you more likely to report financial ties that are over certain dollar limits? & 8 & 23 & 0 \\
\hline $\begin{array}{l}\text { Are you satisfied with relying on disclosures in the scientific literature to get information on } \\
\text { funding and financial ties? }\end{array}$ & 14 & 16 & 1 \\
\hline $\begin{array}{l}\text { If you know a scientist has financial ties to a company whose product he/she is testing, are } \\
\text { you more skeptical of the research findings? }\end{array}$ & 27 & 3 & 1 \\
\hline Do you make any distinctions between ties to for-profit companies and non-profit or public groups? & 18 & 11 & 2 \\
\hline Are there any pressures on you that influence your ability to report financial ties and research? & 8 & 23 & 0 \\
\hline $\begin{array}{l}\text { Do you feel that disclosure of financial ties in the lay press might pressure researchers to } \\
\text { sever financial ties? }\end{array}$ & 13 & 17 & 1 \\
\hline
\end{tabular}


A few journalists said they routinely ask about financial ties but then, together with editors, make a judgment about its relevance to the particular story. Often, the decision was made to omit the financial tie information from the final published story. In addition, 27 of the 31 respondents said that a known financial tie would make them more skeptical of the research, while 3 said they would not be any more skeptical, and 1 declined to choose (Table 2). Those who grow more skeptical often mentioned that they were aware of previous studies demonstrating that financial ties influence the outcomes of research, either openly or subtly, consciously or not. One journalist stated, 'there are ample examples from the past of companies pressuring researchers.' Another stated, 'the relationship may color judgment or affect trial design in subtle ways'. Those who said they were not affected by a financial tie said they started out very skeptical, or that it would depend on the research results, or that some scientists were above compromise.

We asked an open-ended question about the definition of financial ties. Two respondents said they did not understand the question and did not provide a definition. Almost all others mentioned at least research funding. Other types of financial ties listed were (1) plans to start a related private company, (2) consulting fees, (3) stock ownership, (4) participation in advisory boards, (5) free continuing education, (6) speaking fees, (7) current or planned patent holding, and (8) profit sharing. One journalist said that the definition of a financial tie is a gray area that is often decided for each story. Another reported that research funding may be identified but that readers are not interested in this information, and any other ties would not usually be included in the published story. When asked whether they distinguish between private and nonprofit or public financial ties, 18 said yes and 11 said no, with 2 refusing to choose (Table 2). Some journalists acknowledged that the profit motive was powerful and so led to a distinction. Others felt that the line was blurry, that nonprofits can also have narrow or biased interests. One journalist observed that his or her employer was a private company as well. Another was not too worried about research funding from the government, such as funding from the National Institutes of Health.

We also asked whether anyone would report financial ties above a specific dollar threshold, and asked for specific amounts that would be reported. Eight journalists said yes, they would have specific dollar amounts, while 23 said no (Table 2). Seven actually chose a dollar amount: 2 writers said nothing specific, 2 said that the tie should be more than $\$ 10000$, none said between $\$ 5000$ and $\$ 10000,1$ said $\$ 2000$ to $\$ 5000$, 2 said between $\$ 500$ and $\$ 2000$, and none chose a threshold of less than $\$ 500$. One journalist commented that the larger the tie, the more likely it would get reported, but did not choose a specific amount. Another said that dollar amounts would rarely be made available, so if it was known he/she would surely report it.

We asked journalists whether they believed that reporting financial ties in the press might cause researchers to sever the tie. Other than 2 abstentions, no one responded unequivocally; this is a gray area that elicited open-ended responses that can be categorized as 'weak yes' (7), 'weak no' (18), and truly mixed or 'depends' (4). Specific responses among the weak yes group mentioned bad publicity and damaged reputations. Those among the weak no group often mentioned that corporate funding of research was common and even necessary. One mentioned that universities encourage faculty to start businesses, and another said that researchers are under tremendous pressure to seek funding from all sources. Many felt a newspaper article would not be important enough to change financial relationships. One respondent reported a recent case in which a hospital receiving pharmaceutical funding for continuing education courses decided to create a separate organization to receive the funding indirectly because of controversy regarding conflicts of interest.

\section{Methods for discovering financial ties}

The journalists responded to several questions related to strategies and methods for discovering financial tie information for science stories. First, we asked where the initial ideas for health and science stories are found. The 31 respondents were asked to select multiple sources if relevant from a list of 4 : scientific journal (29), press release (28), unsolicited information (26), and other (17). One journalist noted: 'In all honesty, everything is a story, ideas come at us from all sides'. Hence, it is not surprising that eleven journalists selected all 4 choices, and most others selected a combination of 3. Other sources mentioned specifically included cultivated relationships, popular media, conferences and scientific meetings, questions inspired by past stories written, and self-directed research.

Because scientific journals increasingly disclose financial ties of researchers, the use of scientific journals as sources suggests that journalists may have financial tie information readily available. When asked whether they are satisfied with relying on disclosures in scientific journals for financial tie information, the group was almost evenly split, as 14 said yes, 16 said no, and 1 abstained (Table 2). We also asked an openended question about how financial ties are investi- 
gated. In response, 3 journalists said they do not investigate them and a fourth does not go beyond the scientific journal disclosure. The other most frequently mentioned strategy for discovering financial ties was to ask the researcher and the funder directly. Most said that they would report the scientist's first response unless evidence of dishonesty appeared, but 1 journalist tried to ask additional probing questions.

Other methods mentioned were checking scientific literature other than the study being reported, conducting internet searches, checking with nonprofit groups that track this information, such as the Center for Science in the Public Interest's 'Integrity in Science' list (www.cspinet.org/integrity/), and obtaining public records, such as those available from universities or government agencies through the freedom of information process or sponsored research office. One creative respondent interviewed deans and graduate student researchers, and scanned state appropriations bills and other state-level legal records. Another journalist stated that mastering the scientific subject matter for the story left little time to do investigations into financial ties.

\section{Barriers and incentives to reporting financial ties}

The third purpose of our survey was to explore barriers and incentives for journalists to report on financial ties in scientific research. We asked about the positive and negative aspects of reporting financial ties. Positive aspects mentioned were very similar among 30 journalists, and included addressing the public's right to know, better informing readers, providing greater transparency and balance, and improving the reader's understanding of health and safety issues. One respondent did not list any positive aspects. On the other hand, 9 journalists declared no negative aspects to reporting on financial ties. Five others listed only space constraints as a challenge. Other negative aspects listed included damaging the reputation of a scientist, spreading misinformation, distracting from the main story, overly simplifying complex circumstances, having uncomfortable conversations, and generating reader disinterest.
We also investigated the possible influence of other players and stakeholders in journalism. We asked about the role of editors, financial sponsors of the publication, the public, or anyone else in the decision to report financial ties. The results are listed in Table 3. If influence is present, it can be either positive or negative - in other words, encouraging reporting of ties or discouraging it. Unsurprisingly, editors were mentioned as having the most influence. Of the 31 journalists, 21 said that editors were influential over the decision to report financial ties, with 13 stating that they encouraged or even required the practice, 1 saying that the editor was discouraging (limits time for research), and 7 reporting that it would depend on space, deadlines, and priorities. Only 4 said that financial sponsors of the journalist's publication have any influence. One journalist stated that it was a 'very distant, very little role'. The extent of the influence of financial sponsors of the newspaper seemed difficult for respondents to explain further: one said, 'depends on the report,' and another said, 'I don't know how to categorize it'.

Another possible influential actor is the public. Fifteen respondents agreed that the public is influential, 8 reported no public influence, and 8 declined to answer. Of the set that reported an influential public, 8 said that the public encouraged the reporting of financial ties and 7 stated that they discouraged it. Two respondents said that the public, described by one journalist as a 'focused and vocal minority,' will demand this information directly. Others listed the right of the general public to be fully informed. One comment about public discouragement revealed that wealthy friends of the publisher or the board might complain. Eleven journalists listed other influences, 4 encouraging, 3 discouraging, and 4 having unpredictable influence. These often included constraints of space and time. Five respondents mentioned the researchers themselves, with some reporting cooperation from the scientists and others reporting reluctance or even the intimidating nature of large important research institutions; another mentioned the encouragement from professional associations for journalists.

Table 3. Influence of possible stakeholders over polled journalists' decisions to report financial ties $(\mathrm{n}=31)$

\begin{tabular}{|c|c|c|c|c|c|}
\hline Player & Yes - encourage & Yes - discourage & Yes - direction unpredictable & Little or no influence & Decline \\
\hline Editor & 13 & 1 & 7 & 9 & 1 \\
\hline Sponsor $^{a}$ & 0 & 0 & 4 & 23 & 4 \\
\hline The public & 8 & 1 & 6 & 8 & 8 \\
\hline Other & 4 & 3 & 4 & 9 & 11 \\
\hline
\end{tabular}




\section{DISCUSSION}

Our survey faced several challenges. The universe of health and science journalists identified by this method was surprisingly small: only 145 journalists produced 1152 newspaper stories in $2 \mathrm{yr}$. In addition, this is a difficult population to survey, as journalists may keep irregular hours, may travel frequently, may change jobs frequently, may have survey fatigue, and may feel too busy to participate in interviews. Some reported that company policy prohibited their participation in a survey study. Nonetheless, we collected extensive comments from 31 journalists and found both agreement and discord on attitudes and practices regarding financial ties in science. This small number of responses casts a shadow of caution over the application of these results. The self- assessment of frequency of reporting financial ties is not in agreement with the literature or our own previous study (Cook et al. 2007). While onethird of these journalists say they almost always or always report ties, our analysis of their printed stories themselves showed that just $38 \%$ reported funders and $11 \%$ reported financial ties of researchers. One reason for this discrepancy may be that the journalists who agreed to participate in our study were more likely to report financial ties than those who did not participate. However, several respondents felt as this journalist did: 'But your survey has me thinking, perhaps I should be asking routinely about funding, even when there isn't an apparent issue.'

One possible point of confusion is the definition of financial ties (Boffey et al. 1999). In fact, the various and nebulous definitions of financial ties utilized by journals, universities, and government agencies was identified as a top priority for addressing conflicts of interests in science in a recent review article, suggesting the broad definition: 'any financial arrangement that compromises, has the capacity to compromise, or has the appearance of compromising trust,' (Tereskerz \& Moreno 2005, p 143). Nevertheless, our study revealed considerable awareness of financial ties and potential conflicts of interest among most of the journalists. We asked the journalists to define financial ties, but while financial ties to industry are one possible source of bias, 'commitment' ties or ideological ties to organizations or issues are another. Most respondents in our study considered the funding of research to be a conflict of interest, and seemed less aware of other types of financial ties that might influence research outcomes. The journalists also displayed a sophisticated understanding of the nonprofit sector as having narrow interests, showed reluctance to choose a dollar amount cutoff point for reporting, and knew about the pervasiveness bias associated with research funding. At the same time, the journalists did not have confidence in their own ability to improve the scientific enterprise with more exposure of financial ties.

These journalists used various methods to find information about financial ties and potential conflicts of interest, including making use of various sources, most frequently the disclosures in scientific journals and direct inquiry of researchers. In our previous study, however, we found that about a quarter of the stories without mention of financial ties had the information readily available in the published scientific literature (Cook et al. 2007). Press releases are another important source of information for journalists, and these also often provide insufficient information on financial ties of researchers (Woloshin \& Schwartz 2002). A few journalists indicated conducting very thorough investigations of financial ties. In addition, the journalists felt influenced by other players in the publishing process, but these influences were both encouraging and discouraging disclosure. Most often mentioned, in response to several open-ended questions, was the public's right to know the complete story, and the public benefit to having all the facts available that may put the research into better context.

Overall, journalists interviewed in the present study display a favorable attitude towards reporting financial conflicts of interest related to research. However, perhaps ideal practices are divergent from actual practices. Journalists themselves increasingly have financial ties to the drug industry; several cash prizes for outstanding journalism are funded by pharmaceutical companies (Schwartz et al. 2008). Attention to ethics will continue to gain relevance. Moreover, corporate stakeholders may deliberately use journalism in a strategy to construct and spread scientific ignorance and controversy about a scientific claim (Stocking \& Holstein 2009). As the personal financial ties of researchers are becoming more prevalent (Campbell et al. 2004, 2007), journalists must continue to seek information on these personal financial ties, as well as direct research funding for a study. These efforts are being facilitated by improvements in the reporting of financial conflicts of interest in both research journals and press releases (Cooper et al. 2006). Journalists should also continue to seek comments from independent experts. To assist journalists in identifying independent sources, one journalist compiles and updates a list of scientific experts that have no financial ties to industry (http://healthnewsreview. org; Lenzer 2008, Lenzer \& Brownlee 2008).

\section{CONCLUSIONS}

The journalists polled in the present study, who reported on the top health and science stories of 2004 and 2005, had considerable awareness of the implications of 
potential conflicts of interest, but had divergent investigating and reporting practices attributable to various challenges. These challenges included time, space, difficulty finding objective sources, and editorial priorities. The present study revealed topics for further inquiry. Clearly, there are organizational issues that impact reporting practices and self-reporting. However, questions remain about the relationship between seniority, type of newspaper, size of organization, role of professional training, and the reluctance of corporate media to implicate potential conflicts of interest. The generalizability of our conclusions is limited by the small number of journalists interviewed. Our experience reveals the challenges of surveying this small but important group. Those researchers who seek more robust numbers will need to overcome several challenges, including corporate policies and survey fatigue.

Acknowledgements.We thank S. O'Mara and E. Campbell for data collection assistance. This research was supported by the US National Science Foundation, Award Number 0520691.

\section{LITERATURE CITED}

Ancker JS, Flanagin A (2007) A comparison of conflict of interest policies at peer-reviewed journals in different scientific disciplines. Sci Eng Ethics 13:147-157

Baltimore D (1989) The worsening climate for biological research: is the public losing faith in science? Technology Review 92:22 and 24

Bekelman JE, Li Y, Gross CP (2003) Scope and impact of financial conflicts of interest in biomedical research: a systematic review. JAMA 289:454-465

Berman EP (2008) Why did universities start patenting? Institution-building and the Road to the Bayh-Dole Act. Soc Stud Sci 38:835-871

Bero LA (2005) Tobacco industry manipulation of research. Public Health Rep 120:200-208

Bero L, Oostvogel F, Bacchetti P, Lee K (2007) Factors associated with findings of published trials of drug-drug comparisons: why some statins appear more efficacious than others. PLoS Med 4:e184

Boffey PM, Rodgers JE, Schneider SH (1999) Interpreting uncertainty: a panel discussion. In: Friedman SM, Dunwoody S, Rogers CL (eds) Communicating uncertainty: media coverage of new and controversial science. Lawrence Erlbaum Associates, Nahwah, NJ

Bok D (2003) Universities in the marketplace: the commercialization of higher education. Princeton University Press, Princeton, NJ

Boyd EA, Bero LA (2000) Assessing faculty financial relationships with industry. JAMA 284:2209-2214

Boyd EA, Cho MK, Bero LA (2003) Financial conflict-of-interest policies in clinical research: issues for clinical investigators. Acad Med 78:769-774

> Campbell P (2001) Declaration of financial interests. Nature 412:751

Campbell EG, Powers JB, Blumenthal D, Biles B (2004) Inside the triple helix: technology transfer and commercialization in the life sciences. Health Aff (Millwood) 23:64-76
Campbell EG, Weissman JS, Ehringhaus S, Rao SR, Moy B, Feibelmann S, Goold SD (2007) Institutional academic industry relationships. JAMA 298:1779-1786

Canales MK, Breslau ES, Nelson DE, Ballard-Barbash RR (2008) Did news reporters get it right? Translation of the 2002 hormone study findings. Am J Prev Med 34:61-68

> Caulfield T (2004) The Commercialisation of medical and scientific reporting. PLoS Med 1:e38

Cho MK, Shohara R, Schissel A, Rennie D (2000) Policies on faculty conflicts of interest at US universities. JAMA 284: 2203-2208

Clark F, Illman DL (2006) A longitudinal study of the New York Times Science Times section. Science Communication 27:496-513

Cook DM, Boyd EA, Grossmann C, Bero LA (2007) Reporting science and conflicts of interest in the lay press. PLoS One 2:e1266

> Cooper RJ, Gupta M, Wilkes MS, Hoffman JR (2006) Conflict of interest disclosure policies and practices in peerreviewed biomedical journals. J Gen Intern Med 21: $1248-1252$

> Dana J, Loewenstein G (2003) A social science perspective on gifts to physicians from industry. JAMA 290:252-255

> Drazen JM, Koski G (2000) To protect those who serve [editorial]. N Engl J Med 343:1643-1645

Friedman PJ (2002) The impact of conflict of interest on trust in science. Sci Eng Ethics 8:413-420

Geller G, Bernhardt BA, Gardner M, Rodgers J, Holtzman NA (2005) Scientists' and science writers' experiences reporting genetic discoveries: toward an ethic of trust in science journalism. Genet Med 7:198-205

> Hochman M, Hochman S, Bor D, McCormick D (2008) News media coverage of medication research: reporting pharmaceutical company funding and use of generic medication names. JAMA 300:1544-1550

Hyde J (2006) News coverage of genetic cloning: when science journalism becomes future-oriented speculation. J Commun Inq 30:229-250

Kennedy D (2004) Disclosure and disinterest. Science 303:15

- Kua E, Reder M, Grossel MJ (2004) Science in the news: a study of reporting genomics. Public Underst Sci 13: 309-322

- Kuriya B, Schneid EC, Bell CM (2008) Quality of pharmaceutical industry press releases based on original research. PLoS One 3:e2828

Lenzer J (2008) Truly independent research? BMJ 337:a1332

Lenzer J, Brownlee S (2008) Naming names: is there an (unbiased) doctor in the house? BMJ 337:a930

Lesser LI, Ebbeling CB, Goozner M, Wypij D, Ludwig DS (2007) Relationship between funding source and conclusion among nutrition-related scientific articles. PLoS Med $4: \mathrm{e} 5$

Lexchin J, Bero L, Djulbegovic B, Clark O (2003) Pharmaceutical industry sponsorship and research outcome and quality: systematic review. BMJ 326:1167-1170

McInerney C, Bird N, Nucci M (2004) The flow of scientific knowledge from lab to the lay public: the case of genetically modified food. Sci Commun 26:44-74

> Moynihan R, Sweet M (2000) Medicine, the media and monetary interests: the need for transparency and professionalism. Med J Aust 173:631-634

> Moynihan R, Bero L, Ross-Degnan D, Henry D and others (2000) Coverage by the news media of the benefits and risks of medications. N Engl J Med 342:1645-1650

Pellechia MG (1997) Trends in science coverage: a content analysis ofthree US newspapers. Public Underst Sci 6: 49-68 
Phillips DP, Kanter EJ, Bednarczyk B, Tastad PL (1991) Importance of the lay press in the transmission of medical knowledge to the scientific community. N Engl J Med 325:1180-1183

Rosenstock L, Lee LJ (2002) Attacks on science: the risks to evidence-based policy. Am J Public Health 92:14-18

Schwartz LM, Woloshin S, Moynihan R (2008) Who's watching the watchdogs? BMJ 337:a2535

Schwitzer G (2008) How do US journalists cover treatments, tests, products, and procedures? An evaluation of 500 stories. PLoS Med 5:e95

Singh J, Hallmayer J, Illes J (2007) Interacting and paradoxical forces in neuroscience and society. Nat Rev Neurosci $8: 153-160$

Smith KC, Wakefield MA, Terry-McElrath Y, Chaloupka FJ and others (2008) Relation between newspaper

Editorial responsibility: Stephanie Suhr-Sliester, Oldendorf/Luhe, Germany coverage of tobacco issues and smoking attitudes and behaviour among American teens. Tob Control 17: $17-24$

> Stocking SH, Holstein LW (2009) Manufacturing doubt: journalists' roles and the construction of ignorance in a scientific controversy. Public Underst Sci 18:23-42

$>$ Tereskerz PM, Moreno J (2005) Ten steps to developing a national agenda to address financial conflicts of interest in industry sponsored clinical research. Account Res 12:139-155

Washburn J (2005) University, Inc.: The corporate corruption of American higher education. Basic Books, New York

Winsten JA (1985) Science and the media: the boundaries of truth. Health Aff 4:5-23

Woloshin S, Schwartz LM (2002) Press releases: translating research into news. JAMA 287:2856-2858

Submitted: December 15, 2008; Accepted: February 20, 2009 Proofs received from author(s): April 23, 2009 